\title{
BMI
}

\section{Corticosteroids in the prevention and treatment of acute respiratory distress syndrome (ARDS) in adults: meta-analysis}

\author{
John Victor Peter, physician, ${ }^{1}$ Preeta John, lecturer, ${ }^{2}$ Petra L Graham, lecturer, ${ }^{3}$ John L Moran, senior \\ consultant, ${ }^{4}$ ge Abraham George, lecturer, ${ }^{5}$ Andrew Bersten, professor $^{6}$
}

Department of Medical Intensive Care, Christian Medical College and Hospital, Vellore, India 632004

${ }^{2}$ Department of Surgical Critical Care and Anaesthesia, Christian Medical College and Hospital, Vellore, India

${ }^{3}$ Department of Statistics, Division of Economic and Financial Studies, Macquarie University, Sydney, NSW, Australia

${ }^{4}$ Department of Intensive Care, Queen Elizabeth Hospital, Woodville, SA, Australia 5011

${ }^{5}$ Department of Medicine, Christian Medical College and Hospital, Vellore, India

${ }^{6}$ Department of Critical Care Medicine, Flinders Medical Centre and School of Medicine, Flinders University, Bedford Park, SA, Australia

Correspondence to: J L Moran john.moran@adelaide.edu.au

doi:10.1136/bmj.39537.939039.BE

\section{ABSTRACT}

Objective To systematically review the efficacy of steroids in the prevention of acute respiratory distress syndrome (ARDS) in critically ill adults, and treatment for established ARDS.

Data sources Search of randomised controlled trials (1966-April 2007) of PubMed, Cochrane central register of controlled trials, Cochrane database of systematic reviews, American College of Physicians Journal Club, health technology assessment database, and database of abstracts of reviews of effects.

Data extraction Two investigators independently assessed trials for inclusion and extracted data into standardised forms; differences were resolved by consensus.

Data synthesis Steroid efficacy was assessed through a Bayesian hierarchical model for comparing the odds of developing ARDS and mortality (both expressed as odds ratio with $95 \%$ credible interval) and duration of ventilator free days, assessed as mean difference. Bayesian outcome probabilities were calculated as the probability that the odds ratio would be $\geq 1$ or the probability that the mean difference would be $\geq 0$. Nine randomised trials using variable dose and duration of steroids were identified. Preventive steroids (four studies) were associated with a trend to increase both the odds of patients developing ARDS (odds ratio 1.55, 95\% credible interval 0.58 to 4.05 ; $P$ (odds ratio $\geq 1)=86.6 \%$ ), and the risk of mortality in those who subsequently developed ARDS (three studies, odds ratio $1.52,95 \%$ credible interval 0.30 to 5.94 ; $P$ (odds ratio $\geq 1$ ) $=72.8 \%$ ). Steroid administration after onset of ARDS (five studies) was associated with a trend towards reduction in mortality (odds ratio $0.62,95 \%$ credible interval 0.23 to 1.26 ; $\mathrm{P}$ (odds ratio $\geq 1$ ) $=6.8 \%$ ). Steroid therapy increased the number of ventilator free days compared with controls (three studies, mean difference 4.05 days, $95 \%$ credible interval 0.22 to $8.71 ; \mathrm{P}$ (mean difference $\geq 0)=97.9 \%$ ). Steroids were not associated with increase in risk of infection.

Conclusions A definitive role of corticosteroids in the treatment of ARDS in adults is not established. A possibility of reduced mortality and increased ventilator free days with steroids started after the onset of ARDS was suggested. Preventive steroids possibly increase the incidence of ARDS in critically ill adults.

\section{INTRODUCTION}

The acute respiratory distress syndrome (ARDS) is a life threatening condition with mortality rates of about $40-60 \% .^{12}$ The pathophysiological basis of acute respiratory distress syndrome-excessive and protracted inflammation characterised by increased vascular permeability and extravasation of plasma and leucocyte infiltration ${ }^{1}$-is often systemic, resulting in multiorgan dysfunction and death. Treatment strategies, with the exception of low tidal volume mechanical ventilation, ${ }^{3}$ have had little impact on outcomes. Since inflammation is thought to contribute to the pathogenesis of $\mathrm{ARDS}^{1}$ it is rational to explore modulating therapies for this inflammation, provided the adverse effect of such treatment is not excessive. Corticosteroids, potent anti-inflammatory agents, and immunomodulators, which exert inhibitory effects in several stages of the inflammatory cascade, ${ }^{4}$ would seem to be a logical choice for treatment of ARDS. Clinical outcomes in trials on the role of steroids in $\mathrm{ARDS}^{\mathrm{w1-w5}}$ have varied, however, and two recent systematic overviews on the efficacy of steroids in ARDS have reached opposite conclusions: "current evidence does not support a role for corticosteroids in the management of ARDS in either the early or late stages . .."5 and "prolonged glucocorticoid treatment substantially and significantly improves meaningful patient-centred outcome variables, and has a distinct survival benefit ..."6 Thus the therapeutic status of steroids in ARDS is unclear. We assessed whether steroids are associated with mortality benefit in adults with ARDS. We also determined the effect of steroids on infections and duration of ventilator free days and the role of steroids in preventing the development of ARDS in critically ill adults.

\section{METHODS}

We selected randomised controlled trials in critically ill patients that evaluated steroid treatment compared 


\begin{tabular}{|c|c|c|c|c|c|c|c|c|c|c|c|}
\hline Study & $\begin{array}{l}\text { Randomisa- } \\
\text { tion }\end{array}$ & $\begin{array}{l}\text { Allocation } \\
\text { conceal- } \\
\text { ment }\end{array}$ & Blinding & $\begin{array}{l}\text { Inclusion } \\
\text { and } \\
\text { exclusion } \\
\text { criteria } \\
\text { defined }\end{array}$ & $\begin{array}{c}\text { Similar } \\
\text { baseline at } \\
\text { study entry }\end{array}$ & $\begin{array}{l}\text { Treatment } \\
\text { protocol } \\
\text { clearly } \\
\text { described }\end{array}$ & $\begin{array}{l}\text { Cointerven- } \\
\text { tion that } \\
\text { could affect } \\
\text { outcome }\end{array}$ & $\begin{array}{c}\text { Outcome } \\
\text { definition }\end{array}$ & $\begin{array}{l}\text { Extent of } \\
\text { follow-up } \\
\text { described } \\
\text { clearly }\end{array}$ & ITT analysis & Final score \\
\hline $\begin{array}{l}\text { Weigelt } \\
(1985)^{w 16}\end{array}$ & $0 *$ & 0 & 1 & 1 & 0 & 1 & 1 & 1 & 1 & 0 & 6 \\
\hline $\begin{array}{l}\text { Luce } \\
(1988)^{\mathrm{w} 14}\end{array}$ & 1 & 0 & 1 & 1 & 0 & 1 & 0 & 1 & 1 & 0 & 6 \\
\hline $\begin{array}{l}\text { Bernard } \\
(1987)^{\mathrm{w} 2}\end{array}$ & 1 & 0 & 1 & 1 & 1 & 1 & 0 & 1 & 1 & 0 & 7 \\
\hline $\begin{array}{l}\text { Bone } \\
(1987)^{\mathrm{w} 13}\end{array}$ & 1 & 0 & 1 & 1 & 1 & 1 & 0 & 1 & 1 & 1 & 8 \\
\hline $\begin{array}{l}\text { Schein } \\
(1987)^{\mathrm{w} 15} \dagger\end{array}$ & 1 & 0 & 1 & 1 & 1 & 1 & 1 & 1 & 0 & 0 & 7 \\
\hline $\begin{array}{l}\text { Meduri } \\
(1988)^{\text {w3 }}\end{array}$ & 1 & 0 & 1 & 1 & 1 & 1 & 1 & 1 & 0 & 1 & 8 \\
\hline $\begin{array}{l}\text { Steinberg } \\
(2006)^{\text {w5 }}\end{array}$ & 1 & 0 & 1 & 1 & 1 & 1 & 0 & 1 & 1 & 1 & 8 \\
\hline $\begin{array}{l}\text { Annane } \\
(2006)^{\mathrm{w} 1}\end{array}$ & 0 * & 0 & 1 & 1 & 1 & 1 & 0 & 1 & 1 & 0 & 6 \\
\hline $\begin{array}{l}\text { Meduri } \\
(2007)^{w 4}\end{array}$ & 1 & 0 & 1 & 1 & 0 & 1 & 1 & 0 & 0 & 1 & 6 \\
\hline
\end{tabular}

with no steroid treatment to reduce the incidence of ARDS or to improve the outcome from ARDS. Only trials reporting mortality, incidence of ARDS, or data on ventilation were included. We excluded studies reporting only physiological end points (improvements in gas exchange), descriptive or retrospective cohort studies, studies in children, and studies reporting the use of steroids in fat embolism syndrome. Our search had no language restrictions. We classified trials into two groups: preventive steroid treatment in critically ill patients to decrease the development of ARDS, and steroid treatment started after the onset of ARDS.

\section{Search strategy and quality assessment}

We carried out an electronic search for the period 1966 to April 2007 through Medline, the Cochrane central

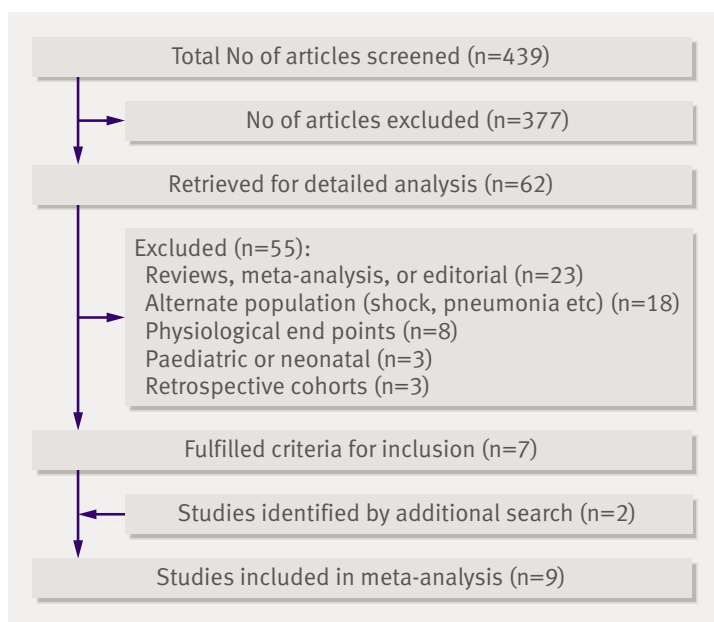

Fig 1 | Flow of studies through systematic review register of controlled trials, the Cochrane database of systematic reviews, the American College of Physicians Journal Club, the health technology assessment database, and database of abstracts of reviews of effects. We restricted the search to studies on adults and used the search terms "ARDS", "adult respiratory distress syndrome", "acute respiratory distress syndrome", "non-cardiogenic pulmonary edema", "respiratory insufficiency", "systemic inflammatory response syndrome", "shock lung", "respiratory failure", "lung injury", "septic shock", "sepsis", AND "steroids", "corticosteroids", "prednisolone", "methyl prednisolone", "hydrocortisone" AND "randomized controlled clinical trials", "controlled trials" and "randomized trials". We reviewed the abstracts of trials generated by the electronic search and retrieved trials pertaining to steroids in ARDS and sepsis for a more detailed evaluation. To identify additional trials we examined review articles, including a Cochrane systematic review on pharmacological therapies in ARDS. ${ }^{7}$ In addition three investigators hand searched the American Journal of Respiratory and Critical Care Medicine, Chest, Critical Care Medicine, European Respiratory Journal, Lancet, New England Journal of Medicine, Intensive Care Medicine, and Thorax. The hand search included an electronic or manual search of the table of contents as well as abstracts of conference proceedings of the various societies published in these journals.

Two investigators extracted predefined data from included studies into standardised data abstraction forms. Quality assessment of these studies was done unblinded by three investigators using a 10 point scoring system (table 1) modified from a previous meta-analysis. ${ }^{9}$ When differences in scoring existed, a 
Table 2 | Main outcome measures evaluated and definition of acute respiratory distress syndrome (ARDS) in included studies

\begin{tabular}{|c|c|c|c|}
\hline Trial & $\begin{array}{l}\text { Year of publication/ } \\
\text { year of study } \\
\text { completion }\end{array}$ & Main outcomes evaluated & Definition of ARDS \\
\hline Weigelt $^{\mathrm{w16}}$ & $1985 / 1983$ & $\begin{array}{l}\text { ARDS, pulmonary dysfunction; } \\
\text { mortality }\end{array}$ & $\begin{array}{l}\text { Partial pressure of oxygen } \leq 250 \mathrm{~mm} \mathrm{Hg} \text { on } 100 \% \text { oxygen, pulmonary } \\
\text { shunt; >25\%, diffuse interstitial oedema on radiographs }\end{array}$ \\
\hline Bone $^{\text {w13 }}$ & $1987 / 1982$ & $\begin{array}{l}\text { Development of ARDS; reversal of } \\
\text { ARDS, mortality }\end{array}$ & $\begin{array}{l}\text { Partial pressure of oxygen } \leq 70 \mathrm{~mm} \mathrm{Hg} \text { on } \geq 40 \% \text { oxygen, bilateral lung; } \\
\text { infiltrates and pulmonary artery wedge pressure }<18 \mathrm{~mm} \mathrm{Hg}\end{array}$ \\
\hline Schein ${ }^{\text {15 }}$ & $1987 / 1982$ & $\begin{array}{l}\text { Complement activation; } \\
\text { complement levels with steroid }\end{array}$ & $\begin{array}{l}\text { Diffuse pulmonary infiltrates, } \mathrm{PaO}_{2}: \mathrm{FiO}_{2} \text { ratio }<160 \text {; pulmonary artery } \\
\text { wedge pressure } \leq 15 \mathrm{~mm} \mathrm{Hg}\end{array}$ \\
\hline Luce $^{\text {w14 }}$ & $1988 / 1986$ & $\begin{array}{l}\text { Development of lung injury; } \\
\text { mortality }\end{array}$ & $\begin{array}{l}\text { New onset diffuse pulmonary infiltrates, } \mathrm{PaO}_{2} / \mathrm{PAO}_{2} \text { ratio }<0.3 \text {, pulmonary } \\
\text { artery wedge pressure } \leq 18 \mathrm{~mm} \mathrm{Hg}\end{array}$ \\
\hline Bernard $^{\mathrm{w} 2}$ & $1987 / 1985$ & $\begin{array}{l}\text { Mortality, oxygenation; changes on } \\
\text { radiographs, lung compliance }\end{array}$ & $\begin{array}{l}\text { Partial pressure of oxygen } \leq 70 \mathrm{~mm} \mathrm{Hg} \text { on }>40 \% \text { oxygen, } \mathrm{PaO}_{2} / \mathrm{PAO}_{2} \text { ratio } \\
<0.3 \text {, bilateral lung infiltrates, pulmonary artery wedge pressure } \leq 18 \mathrm{~mm} \\
\mathrm{Hg}\end{array}$ \\
\hline Meduriw3 & $1998 / 1996$ & $\begin{array}{l}\text { Improvement in lung injury score, } \\
\text { mortality }\end{array}$ & American-European consensus definition* \\
\hline Steinberg ${ }^{\mathrm{w} 5}$ & $2006 / 2003$ & $\begin{array}{l}60 \text { day mortality, ventilator free } \\
\text { days, days without organ failure }\end{array}$ & American-European consensus definition* \\
\hline Annane $^{\mathrm{w} 1}$ & 2006/1999 & $\begin{array}{l}28 \text { day survival distribution; } \\
\text { mortality, ventilator free days }\end{array}$ & $\begin{array}{l}\text { Bilateral infiltrates on radiographs, } \mathrm{PaO}_{2}: \mathrm{FiO}_{2} \text { ratio <200; pulmonary } \\
\text { artery wedge pressure } \leq 18 \mathrm{~mm} \mathrm{Hg} \text { or no left atrial hypertension }\end{array}$ \\
\hline Meduri $^{\text {w4 }}$ & $2007 / 2002$ & $\begin{array}{l}\text { Improvement in lung injury score at } \\
\text { day } 7\end{array}$ & American-European consensus definition* \\
\hline
\end{tabular}

*Acute onset symptoms with $\mathrm{PaO}_{2}: \mathrm{FiO}_{2}$ ratio $\leq 200 \mathrm{~mm} \mathrm{Hg}$ (regardless of positive end expiratory pressure level), bilateral infiltrates on frontal chest radiograph, and pulmonary artery wedge pressure $\leq 18 \mathrm{~mm} \mathrm{Hg}$ when measured or no clinical evidence of left atrial hypertension. ${ }^{13}$

consensus was reached. Extracted data were reviewed and verified by two investigators before analysis.

\section{Outcome measures}

The primary outcome was hospital mortality or survival to hospital discharge. This end point was difficult to determine, however, as mortality was also reported at 14 to 60 days after the onset of ARDS. The hazard ratio would have been the optimum metric for mortality effect ${ }^{10}$ but was found to be impractical because of the variability in reporting. As the hazard ratio may be approximated from the odds ratio, ${ }^{11}$ we chose the odds ratio as an appropriate metric for the mortality effect. We considered several secondary end points a priori: year of study completion, ventilator free days, improvements in lung injury score, incidence of ARDS in critically ill patients after preventive treatment, and steroid related complications, particularly new infections, pneumonia, hyperglycaemia, and

Table 3 | Baseline characteristics of steroid treatment and non-steroid treatment arms in study patients

\begin{tabular}{|c|c|c|c|}
\hline Characteristic & No of studies & Placebo group & Treatment group* \\
\hline No of patients & 9 & 512 & 561 \\
\hline Mean (SD) age (years) & 8 & $52.2(10.9)$ & $52.2(10.6)$ \\
\hline No of men:No of women & 7 & $228: 222$ & $228: 254$ \\
\hline No (\%) of patients with sepsis & 7 & $192(61.7)$ & $242(67.4)$ \\
\hline Mean (SD) APACHE III scoreł & 3 & $65.8(31.9)$ & $68.6(34.6)$ \\
\hline Lung injury score (SD) at recruitment & 3 & $3.0(0.54)$ & $3.1(0.47)$ \\
\hline $\mathrm{PaO}_{2}: \mathrm{FiO}_{2}$ ratio§ (SD) at recruitment & 4 & $120.7(38.7)$ & $114.6(44.8)$ \\
\hline $\begin{array}{l}\text { No (\%) of patients with shock at } \\
\text { admission }\end{array}$ & 6 & $224(60.2)$ & $245(58.1)$ \\
\hline
\end{tabular}

*Received steroids of varying doses.

†Sepsis as cause of acute respiratory distress syndrome.

†Severity of illness using acute physiology and chronic health evaluation score.

$\S$ Ratio of partial pressure of oxygen to fractional inspired oxygen. neuromuscular dysfunction. Because of selection bias in trial reporting ${ }^{12}$ assessable secondary end points were incidence of ARDS in critically ill patients after preventive treatment with steroids, number of patients developing new infections or pneumonia, number of ventilator free days, and year of study completion.

\section{Definitions}

ARDS was defined after the 1994 American-European consensus definition ${ }^{13}$; we retrieved earlier studies to establish consistency with this definition. Secondary infections were defined generally as a positive culture from a normally sterile site. As the time span of the studies was 20 years, we anticipated revisions of the definitions for secondary infections - for example, the use of quantitative cultures in more recent years. The duration of ventilator free days was defined as the number of days patients were alive and breathing without assistance during the 28 days after onset of ARDS, and was presented in the studies as mean (standard deviation) days.

\section{Statistical analysis}

We used Bayesian random effects models ${ }^{14}$ to assess the effect of steroids compared with control on mortality, proportion of patients who developed ARDS, new infections, and pneumonia, expressed as odds ratios with $95 \%$ credible intervals. These methods were most appropriate for the binary outcome data reported since some studies had small sample sizes and the normality assumptions associated with commonly used (frequentist) meta-analysis techniques were not appropriate. Furthermore, Bayesian methods allowed heterogeneity to be adequately incorporated into the analysis. We used a model for summary statistics to assess the overall mean difference (steroid treatment 


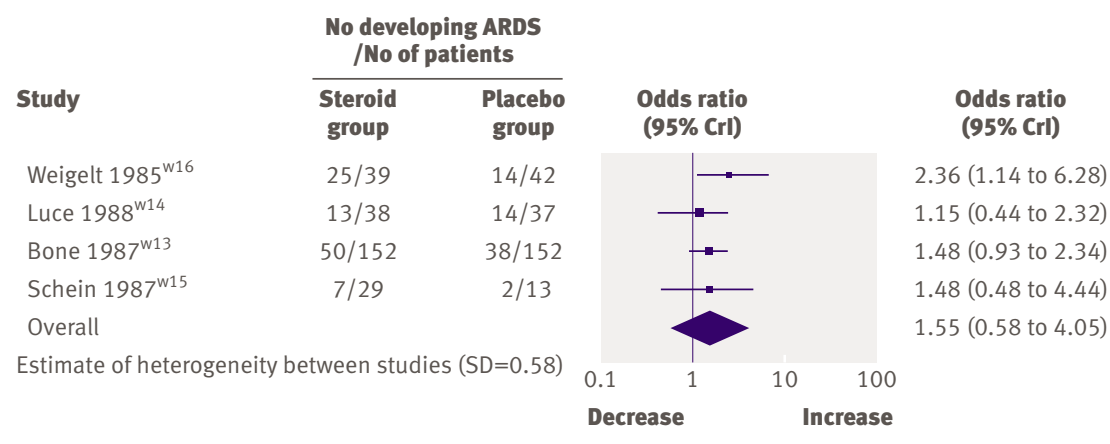

$\overline{\text { Fig } 2}$ Effect of preventive steroids on proportion of patients developing acute respiratory distress syndrome (ARDS) presented heterogeneity as the standard deviation between studies. For all analyses a standard deviation close to 0 indicates little heterogeneity, whereas for the odds ratio meta-analyses a standard deviation of more than 1 might be considered to reflect substantial heterogeneity. Similarly, for the mean difference analysis, a standard deviation greater than, for example, 10 might be considered to indicate substantial heterogeneity. Publication bias was not formally assessed, as the two subgroups each had fewer than 10 studies. ${ }^{15}$

We analysed the data with WinBUGS ${ }^{16}$ using three simultaneous runs of the program with disparate starting values. The first 100000 iterations were discarded and results were reported as posterior medians and intervals on the basis of a further 100000 iterations. We used various diagnostics available in the package Bayesian Output Analysis to assess convergence. ${ }^{17}$ In all cases we found no evidence against convergence. We used the same diffuse priors as described elsewhere ${ }^{14}$ for the odds ratio models and the metaregressions. A diffuse or non-informative prior should not greatly influence the results and reflects little or no prior belief about a particular problem. Mathematically diffuse priors aim to have about equal probability over all plausible values of the variable. For the mean difference model we placed a non-informative normal prior distribution with mean 0 and variance $10^{5}$ on the overall mean difference. A normal distribution with mean 0 and variance of 13.5 and truncated below 0 was placed on the variable for

Table $4 \mid$ Study characteristics, quality scores, and mortality data of included studies assessing steroids for prevention and treatment of acute respiratory distress syndrome (ARDS)

\begin{tabular}{|c|c|c|c|c|c|c|c|c|c|c|c|}
\hline \multirow{3}{*}{$\begin{array}{l}\text { Reference } \\
\text { (year of study } \\
\text { completion) }\end{array}$} & \multirow{3}{*}{$\begin{array}{l}\text { Inclusion and } \\
\text { exclusion criteria } \\
\text { specified }\end{array}$} & \multirow{3}{*}{$\begin{array}{l}\text { Randomisation } \\
\text { mode }\end{array}$} & \multirow{3}{*}{$\begin{array}{l}\text { Mortality } \\
\text { end point }\end{array}$} & \multirow{3}{*}{$\begin{array}{l}\text { Intention to treat } \\
\text { analysis* }\end{array}$} & \multirow{3}{*}{$\begin{array}{l}\text { Quality } \\
\text { score }\end{array}$} & \multicolumn{2}{|c|}{ No of patients } & \multicolumn{4}{|c|}{ Mortality } \\
\hline & & & & & & \multirow{2}{*}{$\begin{array}{l}\text { Placebo } \\
\text { group }\end{array}$} & \multirow{2}{*}{$\begin{array}{l}\text { Steroid } \\
\text { group }\end{array}$} & \multicolumn{2}{|c|}{ Placebo group } & \multicolumn{2}{|c|}{ Steroid group } \\
\hline & & & & & & & & Dead & Alive & Dead & Alive \\
\hline $\begin{array}{l}\text { Weigelt } 1985^{\mathrm{w} 16} \\
(1983)\end{array}$ & Yes & Randomised $†$ & NA & No & 6 & 42 & 39 & 6 & $8 \ddagger$ & 11 & $14 \ddagger$ \\
\hline $\begin{array}{l}\text { Bone } 1987^{w 13} \\
(1985)\end{array}$ & Yes & $\begin{array}{l}\text { Computer } \\
\text { generated }\end{array}$ & 14 days & Yes & 8 & 152 & 152 & 8 & $30 \ddagger$ & 26 & $24 \ddagger$ \\
\hline $\begin{array}{l}\text { Schein } 1987^{\text {w15 }} \\
(1982)\end{array}$ & Yes & $\begin{array}{l}\text { Computer } \\
\text { generated }\end{array}$ & Hospital§ & No & $7 ף$ & 13 & $29^{\star \star}$ & NA & NA & NA & NA \\
\hline $\begin{array}{l}\text { Luce } 1988^{\text {w14 }} \\
\text { (1986) }\end{array}$ & Yes & $\begin{array}{l}\text { Computer } \\
\text { generated }\end{array}$ & Hospital & No & 6 & 37 & 38 & 12 & $2 \ddagger$ & 9 & $4 \ddagger$ \\
\hline $\begin{array}{l}\text { Bernard } 1987^{\mathrm{w} 2} \\
\text { (1985) }\end{array}$ & Yes & $\begin{array}{l}\text { Computer } \\
\text { generated }\end{array}$ & 45 days & No & 7 & 49 & 50 & 31 & 18 & 30 & 20 \\
\hline $\begin{array}{l}\text { Meduri } 1998^{\text {w3 }} \\
\text { (1996) }\end{array}$ & Yes & $\begin{array}{l}\text { Computer } \\
\text { generated }\end{array}$ & Hospital & Yes & 8 & 8 & 16 & 5 & 3 & 2 & 14 \\
\hline $\begin{array}{l}\text { Steinberg } 2006^{\mathrm{w} 5} \\
(2003)\end{array}$ & Yes & $\begin{array}{l}\text { Computer } \\
\text { generated }\end{array}$ & 60 days & Yes & 8 & 91 & 89 & 26 & 65 & 26 & 63 \\
\hline $\begin{array}{l}\text { Annane } 2006^{\mathrm{w} 1} \\
\text { (1999) }\end{array}$ & Yes & $\begin{array}{l}\text { Computer } \\
\text { generated }\end{array}$ & Hospital & No & 6 & 92 & 85 & 67 & 25 & 54 & 31 \\
\hline $\begin{array}{l}\text { Meduri } 2007^{\mathrm{w} 4} \\
(2002)\end{array}$ & Yes & $\begin{array}{l}\text { Computer } \\
\text { generated }\end{array}$ & Hospital & Yes & 6 & 28 & 63 & 12 & 16 & 15 & 48 \\
\hline
\end{tabular}

$\mathrm{NA}=$ not available. None of the studies reported allocation concealment. All studies reported blinding.

*Specified in text.

†Not clearly specified.

IMortality data for patients developing ARDS only presented for these studies.

$\S$ Original publication ${ }^{8}$ presented hospital mortality data, however mortality related to acute respiratory distress syndrome was not available.

TQuality score derived from original publication. ${ }^{8}$

** Includes patients treated with methylprednisolone or dexamethasone. 


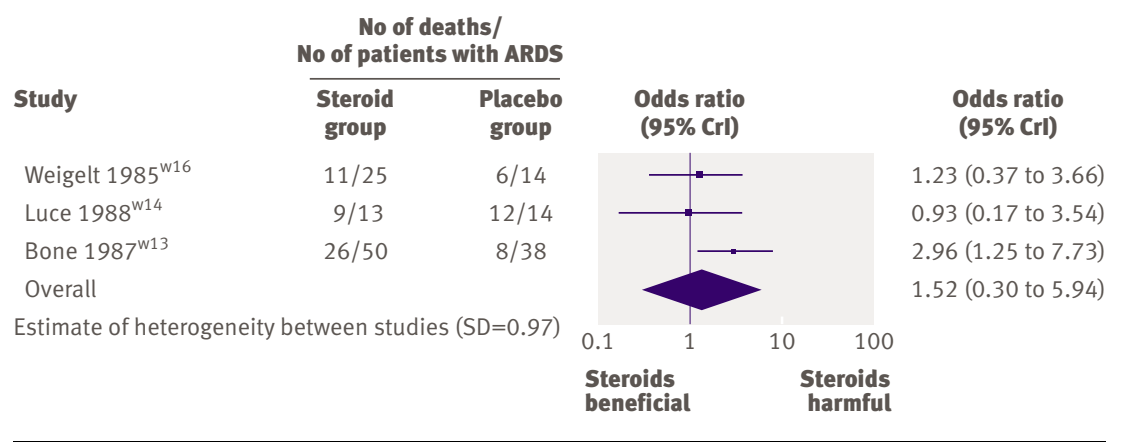

Fig 3 Subsequent mortality in those who developed acute respiratory distress syndrome

standard deviation between studies. ${ }^{18}$ Such a distribution was derived from the notion that the median difference between any two studies was about four days and that a difference of more than 11 days would be extremely unlikely. To determine the influence on the overall results we also undertook a sensitivity analysis in which the priors were made even less informative.

\section{RESULTS}

Of the 7093 articles screened on ARDS or sepsis, 439 pertained to steroids in either condition. One investigator reviewed the abstracts of these articles and 62 articles were retrieved for further assessment by three investigators. Fifty five studies were excluded, including two controlled retrospective studies (fig 1), ${ }^{\mathrm{w} 6 \mathrm{w} 7}$ a randomised trial of steroids in severe community acquired pneumonia, ${ }^{19}$ and five other prospective trials identified by an additional search (see bmj.com). w8-w12 This left nine studies, including two identified by an additional search. Four studies evaluated the preventive use of steroids in critically ill patients ${ }^{\mathrm{w} 13-}$ ${ }^{\text {w16 }}$ and five assessed the role of steroids after the onset of ARDS. ${ }^{\text {wl-w5 }}$ The definitions of ARDS in the studies done before the publication of the American-European consensus definition ${ }^{13}$ were generally consistent with the consensus definition (table 2). The treatment and control arms had similar baseline characteristics (table 3). Table 4 presents a summary of the study characteristics and quality scores; the lag time from study completion to publication ranged from two to seven years. The reporting of mortality was variable. The steroid dose ranged from methylprednisolone $1 \mathrm{mg} / \mathrm{kg} / \mathrm{day}$ to $120 \mathrm{mg} / \mathrm{kg} /$ day (or equivalent doses of hydrocortisone or dexamethasone) administered from four hours to 30 days (table 5).

The credible interval for the preventive use of steroids in critically ill patients included 1 , indicating that a null effect could not be ruled out. The probability (odds ratio $\geq 1$ ) was $86.6 \%$ suggesting some evidence of an association between steroid therapy and the subsequent development of ARDS: four studies, odds ratio 1.55 (95\% credible interval 0.58 to 4.05$)$; SD 0.58 for variability between studies (table 6 and fig 2). Similarly, the probability suggested a weakly increased risk of death associated with steroid therapy in patients who developed ARDS: probability (odds ratio $\geq 1$ ) $=72.8 \%$ (table 6 and fig 3 ), although again the credible interval included 1.

In the five therapeutic studies the probability that the odds ratio was one or more was small indicating that giving corticosteroids after the onset of ARDS was associated with a trend (table 6 and fig 4 ) to reduced mortality (overall odds ratio $0.62,95 \%$ credible interval 0.23 to 1.26 , probability (odds ratio $\geq 1$ ) $=6.8 \%$ ), although the credible interval included 1 so that a null effect could not be ruled out. Some heterogeneity was evident between the studies (standard deviation 0.53 ). Steroid therapy was associated with substantially more ventilator free days (three studies) compared with controls (mean difference 4.05 days, 95\% credible interval 0.22 to 8.71 , probability (mean difference $\geq 0$ ) $=97.9 \%, \mathrm{SD} 2.39$ ). When the effect of moderators (time or dose of steroid therapy, year of study completion) on outcomes was explored in the five therapeutic studies, no evidence was found of an association between odds of mortality and time to treatment (fig 4) in (log) hours; $\beta($ time $)=-0.08(95 \%$ credible interval -1.00 to 0.62$)$, probability $(\beta \geq 0)=38.7 \%$; total steroid dose; $\beta$ (dose) $=0.06(95 \%$ credible interval -0.94 to 0.97$)$, probability $(\beta \geq 0)=57.8 \%$; or year of study completion;

Table $\mathbf{5}$ | Steroid dose, type, duration, and total dose used in adults with acute respiratory distress syndrome (ARDS) in included studies

\begin{tabular}{|c|c|c|c|c|c|c|c|}
\hline Weigelt $^{\mathrm{w} 16}$ & Methylprednisolone & Preventive & 3 & 3 & 120 & 48 & 240 \\
\hline Bone $^{\text {w13 }}$ & Methylprednisolone & Preventive & 2 & 2 & 120 & 24 & 120 \\
\hline Schein $^{\text {w15 }}$ & $\begin{array}{l}\text { Methylprednisolone; } \\
\text { dexamethasone }\end{array}$ & Preventive & NA & $17.5(5.4)$ & $30-60 ; 6$ & $4 ; 4$ & $30-60 ; 30-60 \dagger$ \\
\hline Luce $^{\mathrm{w} 14}$ & Methylprednisolone & Preventive & $1.7(0.5)$ & $1.1(0.2)$ & 120 & 24 & 120 \\
\hline Bernard $^{\mathrm{w} 2}$ & Methylprednisolone & Therapeutic & 28.9 & 32.5 & 120 & 24 & 120 \\
\hline Meduriw3 $^{\text {w3 }}$ & Methylprednisolone & Therapeutic & $211.2(28.2)$ & $225.6(21.6)$ & $2 \ddagger$ & $768 \S$ & $42.5 \S$ \\
\hline Steinberg ${ }^{\mathrm{w} 5}$ & Methylprednisolone & Therapeutic & $271.2(96)$ & $271.2(91.2)$ & $2 \ddagger$ & $716 \S$ & $40 \S$ \\
\hline Annane $^{\mathrm{w} 1}$ & Hydrocortisone & Therapeutic & NA & NA & 200 mg/day & $168 \S$ & $5 \pi$ \\
\hline Meduriw4 $^{4}$ & Methylprednisolone & Therapeutic & 72 & 72 & $1 \ddagger$ & $672 \S$ & 20 \\
\hline
\end{tabular}

$\mathrm{NA}=$ not available.

*Whether steroids were given to critically ill patients before onset of ARDS (preventive) or after onset of ARDS (therapeutic).

†Calculated on basis of $0.8 \mathrm{mg}$ of dexamethasone $=4 \mathrm{mg}$ of methylprednisolone.

łInitial starting dose that was subsequently tapered.

$\S$ Calculated values from text.

ףCalculated on basis of weight $70 \mathrm{~kg}$ and converted for methylprednisolone. 
Table 6 | Summary of outcomes in included studies of steroids compared with placebo in prevention and treatment of adults with acute respiratory distress syndrome (ARDS)

\begin{tabular}{|c|c|c|c|c|c|c|}
\hline \multirow[b]{2}{*}{ Outcome variable } & \multirow[b]{2}{*}{ No of studies } & \multicolumn{2}{|c|}{ No of patients* } & \multirow[b]{2}{*}{ Odds ratio† $(95 \% \mathrm{Crl})$} & \multirow{2}{*}{$\begin{array}{c}P \text { (odds ratio } \\
\geq 1)(\%)\end{array}$} & \multirow[b]{2}{*}{ SD } \\
\hline & & Control group & Steroid group & & & \\
\hline \multicolumn{7}{|l|}{ Mortality: } \\
\hline Therapeutic use & 5 & 268 & 303 & $0.62(0.23$ to 1.26$)$ & 6.8 & 0.53 \\
\hline Preventive use & 3 & 66 & 88 & $1.52(0.30$ to 5.94$)$ & 72.8 & 0.97 \\
\hline Proportion developing ARDS & 4 & 244 & 258 & 1.55 (0.58 to 4.05$)$ & 86.6 & 0.58 \\
\hline \multicolumn{7}{|l|}{ New infections§: } \\
\hline Therapeutic use & 5 & 268 & 303 & 0.78 (0.41 to 1.69$)$ & 20.9 & 0.37 \\
\hline Preventive use & 2 & 79 & 77 & 1.18 (0.19 to 5.99$)$ & 59.6 & 0.88 \\
\hline $\begin{array}{l}\text { Pneumonia (therapeutic } \\
\text { use) }\end{array}$ & 4 & 219 & 253 & 0.59 (0.14 to 2.82$)$ & 23.1 & 1.34 \\
\hline
\end{tabular}

$\mathrm{Crl}=$ credible interval.

*Number included in analysis.

tOdds ratio for steroids versus placebo.

$\ddagger$ Standard deviation between studies.

§Only number of patients with this outcome taken and not number of episodes.

$\beta$ (completion year $)=-0.01(95 \%$ credible interval -0.17 to 0.14$)$, probability $(\beta \geq 0)=44.1 \%$.

As anticipated, definitions for secondary infections varied considerably (table 7). Steroid therapy was not associated with an increase in the number of patients developing new infections. Within the four available therapeutic studies the trend was towards decreased odds of developing pneumonia (probability (odds ratio $<1)=76.9 \%$, table 6 ); although heterogeneity was substantial (SD 1.34, table 6). Metaregression showed a trend towards an increased number of patients developing new infections as steroid dose increased; across seven studies (two preventive trials and five therapeutic trials), $\beta=0.08$ (95\% credible interval -0.12 to 0.28 ), probability $(\beta \geq 0)=81.2 \%$.

Sensitivity analysis was undertaken in which the prior for the variability between studies was made increasingly less informative. In all cases the point estimates remained stable, the credible interval became wider, and probabilitychanged slightly. This did not affect any of the interpretations given in the results except for that of ventilator free days, in which the credible interval included zero.

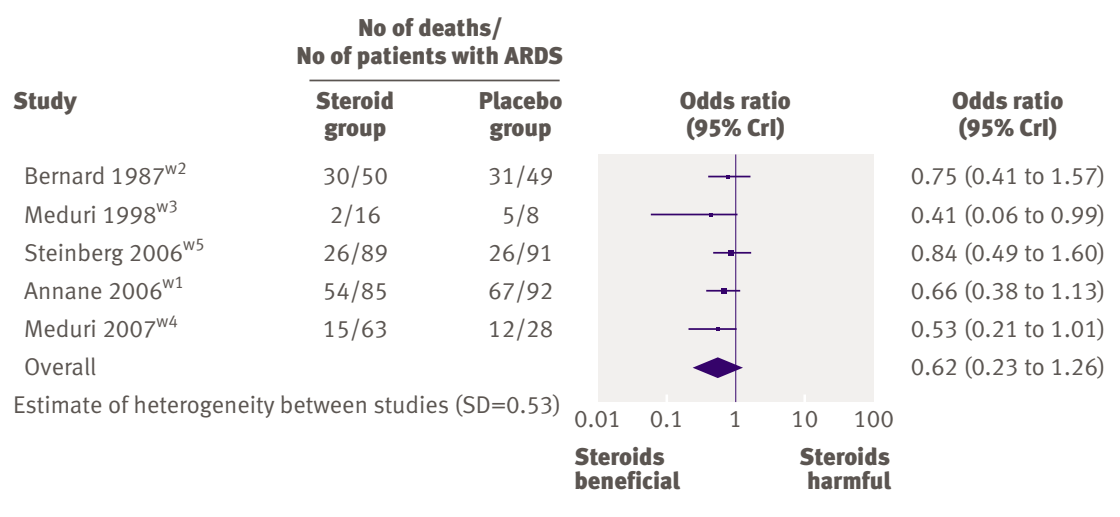

Fig 4 | Effect of therapeutic steroids on mortality in patients with acute respiratory distress syndrome

\section{DISCUSSION}

This systematic review failed to show a convincing treatment effect of steroids in acute respiratory distress syndrome (ARDS), although trends were found for treatment. Although preventive steroid therapy in critically ill patients may have been associated with detrimental effects on the incidence of ARDS and subsequent mortality, a trend was found to benefit when steroids were given after the onset of ARDS; in particular, a reduction in odds of mortality (probability of reduction $93.2 \%$ ). The review, however, showed no discernible time or dose effect of steroids on mortality with the therapeutic use of steroids. Although steroids did not increase overall infection risk, a latent dose dependent effect of steroid therapy on infection rates seemed to exist.

The seemingly differential effect of preventive and therapeutic steroid therapy in ARDS, observed in the current meta-analysis, has been previously suggested, ${ }^{20}$ but the reasons for this are unclear. Key proinflammatory mediators such as tumour necrosis factor $\alpha$ and interleukin 1 have been implicated in the pathophysiology of sepsis with organ dysfunction, the most common cause of ARDS. ${ }^{21}$ In clinical studies, inhibition of these proinflammatory mediators has not improved outcome ${ }^{22}$; indeed, antagonism of tumour necrosis factor $\alpha^{23}$ or interleukin $1^{24}$ increases mortality in some models of bacterial infection, suggesting a key role for their expression in survival from infection. Preventive steroids may not only impede normal homoeostatic response by inhibiting cytokine production, ${ }^{25}$ but also contribute to the pathogenesis of ARDS by stimulating the release of macrophage migration inhibiting factor, a proinflammatory cytokine. ${ }^{26}$ This latter effect remains speculative as release of macrophage migration inhibiting factor by glucocorticoids seems to have a biphasic dose dependency, ${ }^{26-28}$ and protective effects have also been described.$^{29}$ In addition the high doses of methylprednisolone given to the preventive group may have 


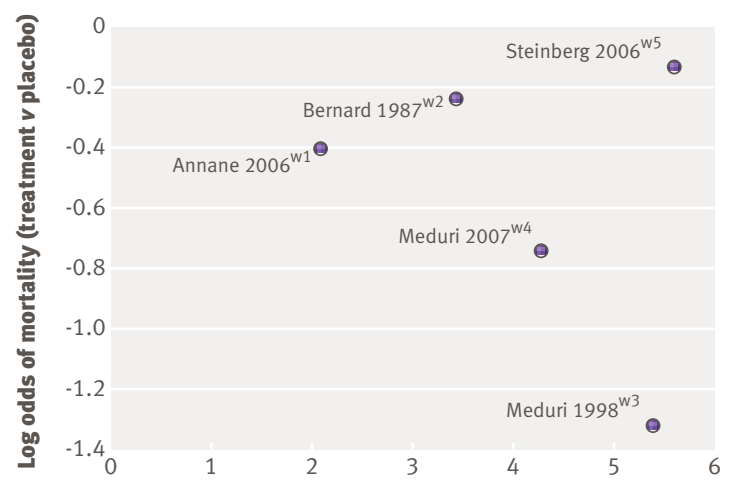

Log time to treatment or placebo (hours)

Fig 5 | Association between odds of mortality and time to starting steroids or placebo

contributed to an increased risk of infection and poorer outcomes. Steroid therapy after the onset of ARDS may, however, have a different effect by modifying the persistent and protracted inflammation that exacerbates lung injury.

The implications of time to starting therapeutic steroids after onset of ARDS are of some importance and have been highlighted in the recent National Heart, Lung, and Blood Institute ARDS clinical trials network report, ${ }^{\mathrm{w} 5}$ where an interaction between time and treatment 14 days after the onset of ARDS was found to be significant. Editorial response ${ }^{430}$ have also embraced a time-difference of steroid effect; benefits occurring with steroid therapy if started within two weeks of ARDS onset and not subsequently. In the individual trials included in the current meta-analysis, the start of steroid therapy ranged from within 72 hours $^{\mathrm{w} 4}$ to four weeks ${ }^{\mathrm{w5}}$ after ARDS onset. Metaregression with initiation time of treatment as a moderator (fig 5) failed to show any influence on mortality. Although such a differential steroid time effect may have biological plausibility, the interpretation of treatment response rates on the basis of data dependent time cut-off points, albeit defined a priori, is problematic. ${ }^{3132}$ Further definition of the optimal time to start steroids is required, possibly by meta-analysis of individual patient data. ${ }^{33}$

Steroids did not seem to have any adverse effect on overall infection rates, including pneumonia, but a trend was found towards increased risk of infection with increasing steroid dose. The enormous variation observed in the steroid dosages ${ }^{20}$ was primarily because studies in the 1980s used high dose (120 mg/ $\mathrm{kg} /$ day methylprednisolone) short duration (24-48 hours) steroids as immunomodulatory therapy whereas prolonged (2-4 weeks) low dose $(1 \mathrm{mg} / \mathrm{kg}$ / day methylprednisolone) anti-inflammatory therapy has been more recently advocated. ${ }^{34}$ Given the complications of high dose steroids, current use is limited to specific (acute) immunological diseases, with little evidence supporting high dose steroids in ARDS. ${ }^{30}$

Secondary outcomes such as lung injury score, incidence of hyperglycaemia, and neuromuscular dysfunction could not be systematically evaluated because of publication bias within studies. ${ }^{35}$ Although the steroid effect on ventilator free days was favourable, and possibly could have an impact on hospital stay and

Table 7| Definition of secondary infections in included studies

\begin{tabular}{|c|c|c|}
\hline Trial & $\begin{array}{l}\text { Year of publication/year of } \\
\text { study completion }\end{array}$ & Definition of infections \\
\hline Weigelt ${ }^{\mathrm{w} 16}$ & $1985 / 1983$ & $\begin{array}{l}\text { Infections monitored included wound, pulmonary, blood, urinary, and intra-abdominal abscesses. } \\
\text { Purulent wound drainage defined wound infections. Pulmonary infection indicated by increases in } \\
\text { temperature, leucocytosis, and radiological infiltrates }\end{array}$ \\
\hline Bone $^{\text {w13 }}$ & $1987 / 1985$ & $\begin{array}{l}\text { No precise definition in text of infections. However, type and site of secondary infections recorded in both } \\
\text { groups }\end{array}$ \\
\hline Schein $^{\text {w15 }}$ & $1987 / 1982$ & $\begin{array}{l}\text { Defined (blinded to therapy) retrospectively after original study by Sprung et al, } 1984^{8} \text { : "Superinfection was } \\
\text { defined as an infection, not present or incubating at the time of admission to the study." No further details } \\
\text { specified }\end{array}$ \\
\hline Luce $^{\text {w14 }}$ & $1988 / 1986$ & $\begin{array}{l}\text { New infections defined as one or more positive cultures of blood or other normally sterile body fluids seven } \\
\text { days after study entry }\end{array}$ \\
\hline Bernard $^{\text {w2 }}$ & $1987 / 1985$ & $\begin{array}{l}\text { Pneumonia diagnosed on basis of history, sputum Gram stain, blood culture, and chest radiograph. Any } \\
\text { infection was defined as new when there was a positive culture from peritoneal fluid, cerebrospinal fluid, } \\
\text { pleural fluid, or circulating blood that grew an organism not suspected of being present in particular body } \\
\text { fluid before patient's entry into study }\end{array}$ \\
\hline Meduri $^{\text {w3 }}$ & 1998/1996 & $\begin{array}{l}\text { Infection surveillance as described earlier. }{ }^{45} \text { Catheter related infections-growth of } \geq 15 \text { colonies on } \\
\text { semiquantitative cultures of subcutaneous portion or tip of catheter. Peritonitis if positive cultures of } \\
\text { peritoneal fluid obtained by paracentesis. Pneumonia-significant growth on quantitative cultures of } \\
\text { bronchoscopic specimens. Primary bacteraemia—positive blood cultures without an identified source. } \\
\text { Sinusitis-computed tomography of sinuses showing air fluid level or opacification and positive cultures } \\
\text { of a maxillary aspirate. Urine culture with } \geq 105 \text { colony forming units/ml for urinary tract infections }\end{array}$ \\
\hline Steinberg ${ }^{\mathrm{w} 5}$ & $2006 / 2003$ & $\begin{array}{l}\text { Any positive culture of material from a normally sterile site (cerebrospinal fluid, blood, pleural fluid, bile } \\
\text { peritoneal fluid or urine with } \geq 105 \text { colony forming units } / \mathrm{ml} \text {. }\end{array}$ \\
\hline Annane $^{\mathrm{w} 1}$ & 2006/1999 & $\begin{array}{l}\text { No precise definition in text of infections. Secondary infections presented in paper include catheter related } \\
\text { infections, nosocomial pneumonia, urinary tract infection, surgical wound infection, and other infections }\end{array}$ \\
\hline Meduri $^{\mathrm{w}}$ & $2007 / 2002$ & Definitions as described for Meduri $1998 / 1996^{45}$ \\
\hline
\end{tabular}




\section{WHAT IS ALREADY KNOWN ON THIS TOPIC}

Corticosteroids as either immunomodulatory or anti-inflammatory agents have potential as therapy in ARDS

A small number of randomised trials and recent systematic reviews have tackled this theory

\section{WHAT THIS STUDY ADDS}

No convincing treatment effect of steroids in ARDS was evident; the optimal dose, timing, and duration of steroid therapy is not established

Meta-analyses based on a small number of trials with sparse data must be cognisant of limitations in estimation of treatment effects; Bayesian estimation would seem suitable

complications, only three studies reported this outcome, and in the sensitivity analysis the credible interval included 0 suggesting the possibility of a null effect. The widening of this interval is not surprising because combination of so few studies results in greater uncertainty in the estimate of the standard deviation between studies and hence wider estimates of the mean difference. Future analysis using a greater number of studies would limit this impact.

\section{Strengths and weaknesses of the review}

The number of trials in this meta-analysis and the number of patients randomised to receive steroids $(\mathrm{n}=561)$ was relatively small, compounded by stratification into two subgroups; preventive and therapeutic. Although commentators ${ }^{3034}$ and a formal review ${ }^{6}$ have considered a randomised trial on steroids in severe community acquired pneumonia ${ }^{19}$ in conjunction with other studies of steroids in ARDS, we did not include this study. In this study, which was stopped early, of the 46 enrolled patients only 23 had multilobar involvement and 34 had a partial pressure of oxygen to fractional inspired oxygen ratio of $<200$. Four patients in the control arm subsequently developed ARDS. Furthermore, it was unclear from the study as to how many patients had bilateral disease. The exclusion of studies on steroid therapy in fat embolism syndrome was justified on the basis that although this is a distinct syndrome that may cause ARDS, the latter is poorly identified in many of these longstanding studies. Fat embolism syndrome is an uncommon cause of ARDS in modern practice and its inclusion may have confounded the interpretation of the effect of steroid treatment on patient cohorts currently considered. Although it would have been preferable to undertake the current meta-analyses adopting the hazard ratio metric ${ }^{10}$ given the disparate time end points, only one of nine studies reported hazard ratios and in the other studies it was not possible to extract relevant data.

In the metaregression of steroid dose effect, the total dose of steroids (equivalent to the potential maximum use of steroids) was used as a moderator variable, as opposed to the first day dose (table 5), because three of the five therapeutic trials ${ }^{\text {w3-w5 }}$ gave substantial initial bolus steroid doses, thus rendering any regression analysis using the first day dose as problematic. The use of total dose of steroids, however, fails to adjust adequately for the occurrence of early deaths in the treatment arm. One possible solution to these potential biases would be the use of steroid free days, normalised, for example, for intended total dose, similar in intent to ventilator free days.

The meta-analysis of Agarwal et $\mathrm{al}^{5}$ found odds ratios of 0.57 (95\% confidence interval 0.25 to 1.32 ) in "early" ARDS and 0.58 (0.22 to 1.53$)$ in "late" ARDS. The conclusions of this meta-analysis are problematic on several grounds. Firstly, the authors combined both observational and randomised trials in their analysis using the DerSimonian and Laird method of moments (frequentist) estimator. This is not optimal for sparse data that may not be normally distributed ${ }^{36}$; the method of Warn et al, ${ }^{14}$ which directly uses binomial likelihoods is apposite for binary outcome data and small samples. Combining observational and randomised trials within a meta-analysis is best undertaken using a hierarchical random effects approach from within the Bayesian paradigm. ${ }^{18}$ Secondly, problems are inherent in grounding analysis on early to late time data dependent cut-off points. Thirdly, the point estimate of mortality effect quoted by the authors is similar to that of the current meta-analysis. Using a frequentist approach, however, the authors were unable to ascribe a probability to the treatment effect and could only conclude a lack of evidence for a treatment effect on the basis of the 95\% confidence interval spanning the null effect.

The "critical appraisal" of Meduri et $\mathrm{al}^{6}$ used fixed effects estimation of the pooled mortality treatment effect with the relative risk metric (relative risk 0.76 , $95 \%$ confidence interval 0.62 to 0.93 ) and included the randomised trial ${ }^{19}$ on steroids in severe community acquired pneumonia (described as early acute lung injury), but did not consider an early trial of steroids in ARDS. ${ }^{\text {w2 }}$ The principal concern was that of heterogeneity and its influence on the pooled mortality estimate: "the analysis for mortality was limited by the significant heterogeneity across the five trials ..."; and its "potential sources" identified by "subgroup analysis based on size of the study . . . timing of initiation of treatment . . . and duration of treatment." Several concerns are raised by this analysis: the identification of heterogeneity (at $\mathrm{P}=0.09$ ) was confounded by aspects of trial conduct, the use of interim analyses in all five trials considered, ${ }^{\text {w1 w3-w519 }}$ and stopping the study early in three. ${ }^{\text {w3 w419 }}$ As previously discussed, ${ }^{37}$ stopping a trial early biases treatment effects in individual trials and the use of stopping rules may induce artificial heterogeneity into overviews of clinical trials and increase the type I error rate in tests of homogeneity ${ }^{38}$; the problems associated with repeated subgroup or empirical analyses of cut-off points are also well known-an increase of type I error rates, overestimation of effect at cut-off point levels, and the conceptual problem of sudden noticeable changes in effect at the various levels. ${ }^{39}$ This is particularly important with respect to the analysis of day 14 time of entry after onset of ARDS in the National Heart, Lung, and Blood Institute ARDS clinical network trials network, ${ }^{\mathrm{w} 5}$ which although 
defined a priori (one of nine "a priori determined covariates ... examined for a treatment interaction"), had the status of a subgroup effect and was thus hypothesis generating, not a definitive treatment recommendation; showing steroid efficacy by empirical subgroup analyses progressively reduced both total sample size and event number, such that the third subgroup analysis (prolonged methylprednisolone treatment of $>1$ week's duration after removing patients randomised after day 14; figure 3 in Meduri et $\left.\mathrm{al}^{6}\right)$ had only 75 events. To ensure more reliable and clinically useful evidence, meta-analyses require appropriately large numbers of events. ${ }^{40}$

We judge aspects of the analyses in these two reviews as problematic and suggest in the context of the limited number of trials, that a Bayesian perspective is both apposite and, unlike conventional frequentist random effects (DerSimonian-Laird) estimation, ${ }^{41}$ able to accommodate heterogeneity, and an odds ratio metric is preferred ${ }^{42}$; a strategy of considering methods based on the random effects model only in the case of heterogeneity ${ }^{6}$ is "inefficient and can lead to understatement of uncertainty about the underlying effect of interest $^{\text {"43 }}$; and in the search for predictors of heterogeneity between studies ${ }^{44}$ meta-regression involving all available studies, not subgroup-analysis, is optimal.

\section{Conclusions}

Some evidence exists for the efficacy of steroid use after the onset of ARDS, without notable side effects such as new infection. We cannot, however, dismiss a null effect. Furthermore, we were unable from the included studies to accurately define the optimal dose, timing, and duration of steroid therapy. Meta-analyses on the basis of a small number of trials with sparse data must be cognisant of limitations in estimation of treatment effects. Thus editorial advocacy to use steroids in ARDS $^{3034}$ must be tempered with some circumspection. Definitive treatment recommendations would seem to depend on further randomised trials or metaanalysis of individual patient data.

Contributors: JVP and JLM conceived, designed, and planned the study. JLM is guarantor. PJ, JVP, and IAG were responsible for the electronic search, data collection, abstraction, hand searching of journals, and data entry. JVP, PJ, and IAG quality assessed the trials. JLM and PLG provided statistical expertise. All authors helped draft the manuscript, carried out a literature search of additional articles, and discussed the results. Funding: None

Competing interests: None declared

Ethical approval: Not required.

Provenance and peer review: Not commissioned; externally peer reviewed.

1 Leaver SK, Evans TW. Acute respiratory distress syndrome. BM] 2007;335:389-94.

2 Milberg JA, Davis DR, Steinberg KP, Hudson LD. Improved survival of patients with acute respiratory distress syndrome (ARDS): 19831993. JAMA 1995;273:306-9.

3 The ARDS Network Authors for the ARDS Network. Ventilation with lower tidal volumes as compared with traditional tidal volumes for acute lung injury and the acute respiratory distress syndrome. The Acute Respiratory Distress Syndrome Network. N Engl J Med 2000;342:1301-8.

4 Suter PM. Lung inflammation in ARDS-friend or foe? N Engl / Med 2006;354:1739-42.
5 Agarwal R, Nath A, Aggarwal AN, Gupta D. Do glucocorticoids decrease mortality in acute respiratory distress syndrome? A metaanalysis. Respirology 2007;12:585-90.

6 Meduri G, Marik P, Chrousos G, Pastores S, Arlt W, Beishuizen A, et al. Steroid treatment in ARDS: a critical appraisal of the ARDS network trial and the recent literature. Intensive Care Med 2007, doi:10.1007/s00134-007-0933-3.

7 Adhikari NK, Burns KE, Meade MO. Pharmacologic therapies for adults with acute lung injury and acute respiratory distress syndrome. Cochrane Database of Syst Rev 2004;(4):CD004477.

8 Sprung CL, Caralis PV, Marcial EH, Pierce M, Gelbard MA, Long WM, et al. The effects of high-dose corticosteroids in patients with septic shock. A prospective, controlled study. N Engl J Med 1984;311:1137-43.

9 Peter JV, Moran JL, Phillips-Hughes J, Graham P, Bersten AD. Effect of non-invasive positive pressure ventilation (NIPPV) on mortality in patients with acute cardiogenic pulmonary edema: a meta-analysis. Lancet 2006;367:1155-63.

10 ParmarMK, Torri V, Stewart L. Extracting summary statistics to perform meta-analyses of the published literature for survival endpoints. Stat Med 1998;17:2815-34.

11 Spruance SL, Reid JE, Grace M, Samore M. Hazard ratio in clinical trials. Antimicrob Agents Chemother 2004;48:2787-92.

12 Williamson PR, Gamble C, Altman DG, Hutton IL. Outcome selection bias in meta-analysis. Stat Methods Med Res 2005;14:515-24.

13 Bernard GR, Artigas A, Brigham KL, Carlet J, Falke K, Hudson L, et al. The American-European Consensus Conference on ARDS. Definitions, mechanisms, relevant outcomes, and clinical trial coordination. $\mathrm{Am}$ J Respir Crit Care Med 1994;149(3 Pt 1):818-24.

14 Warn DE, Thompson SG, Spiegelhalter DJ. Bayesian random effects meta-analysis of trials with binary outcomes: methods for the absolute risk difference and relative risk scales. Stat Med 2002;21:1601-23.

15 Sterne JA, Gavaghan D, Egger M. Publication and related bias in metaanalysis: power of statistical tests and prevalence in the literature. Clin Epidemiol 2000;53:1119-29.

16 Lunn DJ, Thomas A, Best N, Spiegelhalter D. WinBUGS-a Bayesian modelling framework: concepts, structure, and extensibility. Stat Comput 2000;10:325-37.

17 Smith BJ. Bayesian output analysis program (BOA). www.publichealth.uiowa.edu/boa/ 2005.

18 Sampath S, Moran IL, Graham P, Rockliff S, Bersten AD, Abrams KR. The efficacy of loop diuretics in acute renal failure: assessment using Bayesian evidence synthesis techniques. Crit Care Med 2007;35:2516-24.

19 Confalonieri M, Urbino R, Potena A, Piattella M, Parigi P, Puccio G, et al. Hydrocortisone infusion for severe community-acquired pneumonia: a preliminary randomized study. Am J Respir Crit Care Med 2005;171:242-8.

20 Fernandes ABS, Zin WA, Rocco PRM. Corticosteroids in acute respiratory distress syndrome. Braz / Med Biol Res 2005;38:147-59.

21 Bersten AD, Edibam C, Hunt T, Moran J, Australian and New Zealand Intensive Care Society Clinical Trials Group. Incidence and mortality of acute lung injury and the acute respiratory distress syndrome in three Australian states. Am J Respir Crit Care Med 2002;165:443-8.

22 Abraham E. Why immunomodulatory therapies have not worked in sepsis. Intensive Care Med 1999;25:556-66.

23 Nakane A, Minagawa T, Kato K. Endogenous tumor necrosis factor (cachectin) is essential to host resistance against Listeria monocytogenes infection. Infect Immun 1988;56:2563-9.

24 Mancilla J, Garcia P, Dinarello CA. The interleukin-1 receptor antagonist can either reduce or enhance the lethality of Klebsiella pneumoniae sepsis in newborn rats. Infect Immun 1993;61:926-32.

25 Han J, Thompson P, Beutler B. Dexamethasone and pentoxifylline inhibit endotoxin-induced cachectin/tumor necrosis factor synthesis at separate points in the signalling pathway. J Exp Med 1993;172:391-4.

26 Donnelly SC, Bucala R. Macrophage migration inhibitory factor: a regulator of glucocorticoid activity with a critical role in inflammatory disease. Mol Med Today 1997;3:502-7.

27 Calandra T, Bernhagen J, Metz CN, Spiegel LA, Bacher M, Donnelly T, et al. MIF as a glucocorticoid-induced modulator of cytokine production. Nature 1995;377:68-71.

28 Maxime V, Fitting C, Annane D, Cavaillon JM. Corticoids normalize leukocyte production of macrophage migration inhibitory factor in septic shock. J Infect Dis 2005;191:138-44.

29 Kevill KA, Bhandari V, Kettunen M, Leng L, Fan J, Mizue Y, et al. A role for macrophage migration inhibitory factor in the neonatal respiratory distress syndrome. / Immunol 2008;180:601-8.

30 Annane D. Glucocorticoids for ARDS: just do it! Chest 2007;131:945-6.

31 Kirsch I, Moncrieff J. Clinical trials and the response rate illusion. Contemp Clin Trials 2007;28:348-51. 
32 Panageas KS, Ben-Porat L, Dickler MN, Chapman PB, Schrag D. When you look matters: the effect of assessment schedule on progression free survival. J Natl Cancer Inst 2007;99:428-32.

33 Smith CT, Williamson PR, Marson AG. An overview of methods and empirical comparison of aggregate data and individual patient data results for investigating heterogeneity in meta-analysis of time-toevent outcomes. J Eval Clin Pract 2005;11:468-78.

34 Meduri GU, Chrousos GP. Effectiveness of prolonged glucocorticoid treatment in acute respiratory distress syndrome: the right drug, the right way? Crit Care Med 2006;34:236-8.

35 Williamson PR, Gamble C. Identification and impact of outcome selection bias in meta-analysis. Stat Med 2005;24:1547-61.

36 Brockwell SE, Gordon IR. A comparison of statistical methods for meta-analysis. Stat Med 2001;20:825-40.

37 Moran JL, Bersten AD, Solomon PJ. Meta-analysis of controlled trials of ventilator therapy in acute lung injury and acute respiratory distress syndrome: an alternative perspective. Intensive Care Med 2005;31:227-35.

38 Bassler D, Ferreira-Gonzalez I, Briel M, Cook DJ, Devereaux PJ, Heels-Ansdell D, et al. Systematic reviewers neglect bias that results from trials stopped early for benefit. J Clin Epidemiol 2007;60:869-73.
39 Altman DG, Lausen B, Sauerbrei W, Schumacher M. Dangers of using "optimal" cutpoints in the evaluation of prognostic factors. J Natl Cancer Inst 1994;86:829-35.

40 Flather MD, Farkouh ME, Pogue JM, Yusuf S. Strengths and limitations of meta-analysis: larger studies may be more reliable. Control Clin Trials 1997;18:568-79.

41 Viechtbauer W. Bias and efficiency of meta-analytic variance estimators in the random-effects model. J Educ Behav Stat 2005;30:261-93.

42 Greenland S. Interpretation and choice of effect measures in epidemiologic analyses. Am J Epidemiol 1987;125:761-8.

43 National Research Council. Combining information: statistical issues and opportunities for research. Washington DC: National Academy Press, 1992.

44 Greenland S. Invited commentary: a critical look at some popular meta-analytic methods. Am J Epidemiol 1994;140:290-6.

45 Meduri GU, Mauldin GL, Wunderink RG, Leeper KV, Jr, Jones CB, Tolley E, et al. Causes of fever and pulmonary densities in patients with clinical manifestations of ventilator-associated pneumonia. Chest 1994;106:221-35.

Accepted: 14 March 2008 